\title{
Lightning Performance of Unshielded 220kV Transmission Lines Equipped with Metal-oxide Arresters
}

\author{
Pengkang Xie*, Zhen Fang \\ State Key Laboratory of Disaster Prevention \& Reduction for Power GridTransmission \& Distribution Equipment, Changsha 410007 \\ China.
}

\begin{abstract}
Overhead ground wires have been proved to be effective to protect conductors from direct lightning strikes, but breakouts of ground wires have been frequently reported. In order to prevent ground wire breakout incidents to happen, unshielded $220 \mathrm{kV}$ lines equipped with metal oxide arresters (MOAs) whole line have been proposed in this paper. After cancelling ground wire, lightning strike risk of transmission lines becomes much higher. In order to improve the anti-lightning abilities of unshielded transmission lines, it is necessary to obtain the lightning energy absorption ability of these MOAs. In this paper, simulation model of MOA equipped unshielded $220 \mathrm{kV}$ transmission line was built, the influences of lightning parameters, striking occurrence point and grounding resistance of transmission tower on the absorbed energy of MOAs were calculated, and the suggested energy absorption ability of MOA was given, which can give references for the improvement of power supply reliability of transmission lines.
\end{abstract}

\section{Introduction}

Overhead ground wires are used to reduce the tripping rate of transmission lines caused by lightning[1,,2]. However, breakouts of renewable energy transmmsion line ground wires have been frequently reported in recent years due to icing, bird damage, corrosion, wind and so on. To solve this problem, transmission lines without overhead ground wires were proposed [3,4], in order to maintain and enhance the lightning protection ability at the same time, metal-oxide arresters(MOAs) are installed on each phase of each tower. Thus, in order to improve the lightning performance of these unshielded transmission lines, lightning performance assessment and proper selection of line arresters are needed, and an accurate calculation of the energy absorption capability of MOAs is necessary[5-8].

Lightning performance assessments of transmission lines have been studied by scholars. In $[7,8]$, the relationship between lightning failure rate and the design and environmental parameters of transmission lines were studied. The detailed modeling of storm characteristics were proposed, and subsequent strokes were considered in lightning failure rate calculation. In [9], equipments such as MOAs have been proposed to improve the lightning performance of transmission lines. However, till now, lightning performance assessment of unshielded transmission lines equipped with MOAs have not been studied, and the subsequent strokes of lightning were not usually considered in energy absorption calculation of MOAs.

For unshielded transmission lines, the probability of direct lightning strikes of conductors increases significantly. Once the the lightning energy absorbed by MOA exceeds its energy absorption ability, MOA failure and lightning trip-out of transmission line will happen[10]. In view of the exiting studies, this paper focuses on the calculation of the relationship between the energy absorption capability of MOAs and the lightning failure rate of unshielded transmission lines. Statistical distribution of lightning parameters and subsequent strokes have been taken into account in the simulation, transient models of various components of $220 \mathrm{kV}$ unshielded transmission lines were built. The influence of grounding resistance, striking point on the absorbed energy of MOAs was analyzed, and the desired MOA energy absorption ability for expected lightning failure rate of the studied $220 \mathrm{kV}$ unshielded lines was obtained. The research of this paper provides a promising way for lightning protection in high mountainous areas.

\section{Lightning parameters}

\subsection{Lightning current parameters}

The equation of cumulative probability distribution of lightningcurrent peak in the target area in recent 10 years is shown in Equation (1)[3], where $I_{\mathrm{p}}$ is the amplitude of lightning current. $\mathrm{a}=23.5$ and $\mathrm{b}=2.67$ are constants determined by lightning activity. Thelightning current amplitude is shown in Figure 1a.

$$
I_{P}=\frac{1}{1+\left(\frac{I}{a}\right)^{b}}
$$




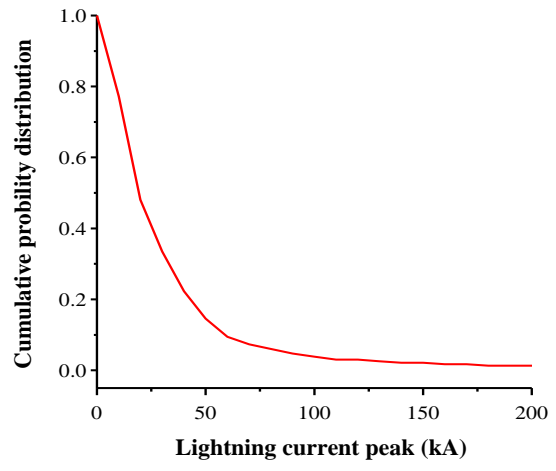

(a) Distribution of Lightning current amplitude (kA)

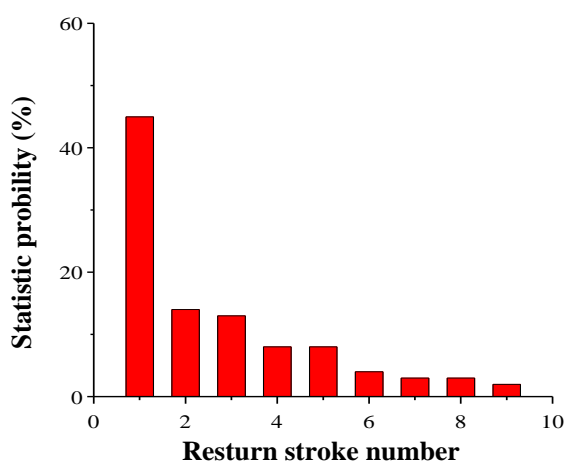

(b) Distribution of cloud-to-ground return-stroke times Fig. 1. statistic data of lightning in target areas

Subsequent strokes in a lightning flash are considered in this paper, statistical number of subsequent strokes in a lightning flash are shown in Fig. 1b, the average number of impulse currents in a lightning flash is 3 , and the max subsequent stroke number is 9 . The average amplitude of return strokes is 0.4 times the amplitude of first stroke[4]. According to the statistic data, in this paper, the waveform of each lightning stroke is set to $2.6 / 50 \mu \mathrm{s}$, the stroke number in each lightning flash is set to 3 , and the time interval between each subsequent strokes $\Delta \mathrm{t}$ is set to $60 \mathrm{~ms}[6]$.

\subsection{Impact area}

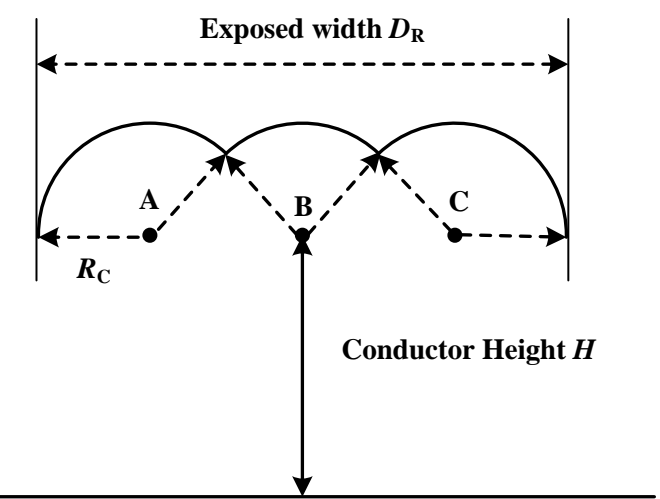

Fig. 2. EGM of the unshielded transmission line

The lightning strike points are randomly distributed on the transmission line corridor. This paper uses Electro geometric model (EGM) to calculate the width of the impact area $Y_{\max }[8]$. As shown in Figure 2, $R_{\mathrm{g}}$ is the striking distances to the ground and $R_{\mathrm{c}}$ is the striking distance to the conductors. The impact area is equal to $Y_{\max } * L$ where $L$ is the length of line span.

\subsection{Modeling of moa and its failure estimation}

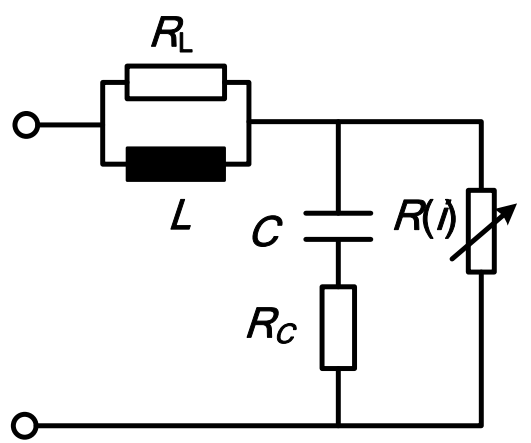

Fig. 3. EGM of the unshielded transmission line

A wide band electric model of MOA is introduced in this paper, shown in Figure 3[7]. The stray parameters are obtained as follow:

$$
\begin{gathered}
L=\frac{h}{n}(\mu H) \\
R_{L}=8 \times 10^{8} L(\Omega) \\
C=12.31 \frac{n}{h}(p F) \\
R_{C}=\frac{0.15 \times 10^{-8}}{C}(\Omega)
\end{gathered}
$$

In the equations above, $n$ means the number of $\mathrm{ZnO}$ varistors connected in parallel, and $h(m)$ is the height of the arresters.

The voltage-current curve of variable resistance $R(i)$ is shown in Figure 4.

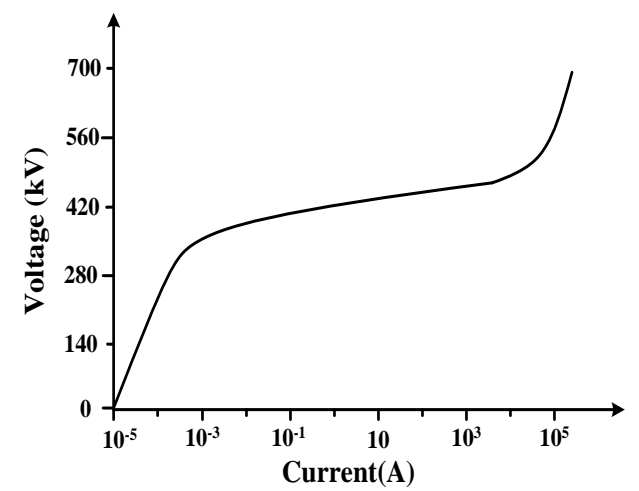

Fig. 4. Voltage-current curve of the variable resistance in the MOA model.

The energy absorbed by MOA during a lightning flash process can be obtained by Equation (6).

$$
W=\int_{t 0}^{t} u_{A}(t) i_{A}(t) d t
$$

Where $W$ means the energy absorbed by arrester, $i_{\mathrm{A}}(\mathrm{t})$ means the instantaneous current flowing through the arrester, $u(\mathrm{t})$ is the residual voltage of the arrester, which 
can be obtained by Figure (3) and Equation (1) to (4). $t_{0}$ and $t$ mean the start and ending time of a lightning flash process.It is assumed that if the absorbed energy exceeds the energy absorption capability of MOA, MOA failure will happen, leading to fault tripping of transmission lines[7].

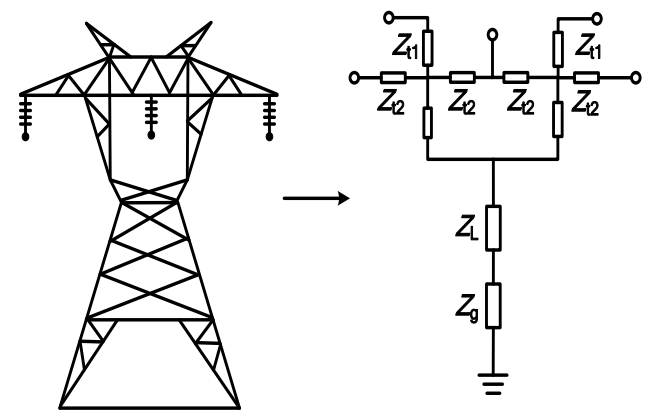

(a) transmission tower

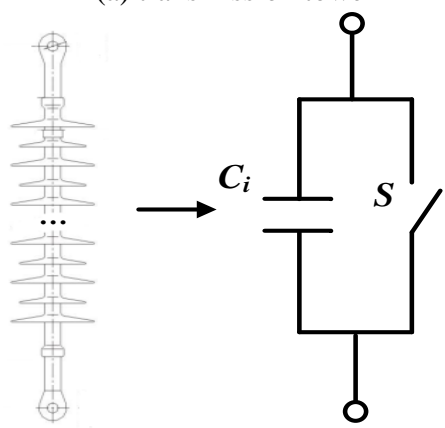

(b) insulator

Fig. 5. Electric model of transmission tower and insulator

The simulationmodelof $220 \mathrm{kV}$ transmission towerand insulator are shown in Figure 5. In which $Z_{\mathrm{t} 1}(200 \Omega)$ is the surge impedance between the tower top and the phase arm, $Z_{\mathrm{t} 2}(150 \Omega)$ is the surge impedance between the insulator suspension point and phase arm, $Z_{\mathrm{L}}(=71.12 \Omega)$ is the impedance of the tower body, and $Z_{\mathrm{g}}$ represents the grounding resistance. In this paper, lumpconstantequivalent circuit is used to model the grounding electrodes, which is approximated to grounding resistance, ranging from 5 to $50 \Omega$ [7].

The insulators on the transmission line are installed in parallel with the MOAs on the transmission tower, which can be modeled as a switch $S$ and a $200 \mathrm{pF}$ capacitor $C_{\mathrm{i}}$, shown in Figure 5 . If the lightning overvoltage exceeds the critical breakdown value $960 \mathrm{kV}$, the switch is closed and flashover happen, which can also lead to fault tripping of transmission lines[6].

\section{Simulation results and analysis}

\subsection{Simulated waveforms}

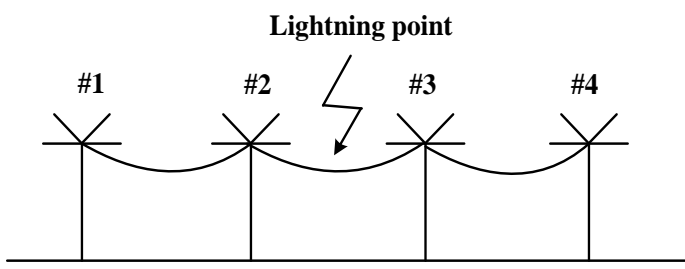

Fig. 6. Simulation condition
Assuming the tower span length to be $400 \mathrm{~m}$, the grounding resistance of each tower to be $15 \Omega$. The lightning current is a $30 \mathrm{kA}, 2.6 / 50 \mu$ s single strike, the lightning flash strikes phase $\mathrm{C}$ conductor between tower 2 and tower $3(100 \mathrm{~m}$ and $200 \mathrm{~m}$ from tower 2 respectively). The waveforms of the negative lightning current, the residual voltage of the MOA, and the simulated transient currents flowing through the nearest arrester are shown in Figure 7. Under lightning currents, the voltage between the insulators equals to the residual voltage of the MOA. From Figure 7(b) and Figure 4, it can be indicated that, because of the nonlinear voltagecurrent characteristics, the residual voltage of MOA are restrained to a low value and will not cause the external insulation flashover of insulators. Due to the refraction and reflection effects of lightning current waves, the flash occurrence point influences little on the current amplitude flowing through the nearest arrester.

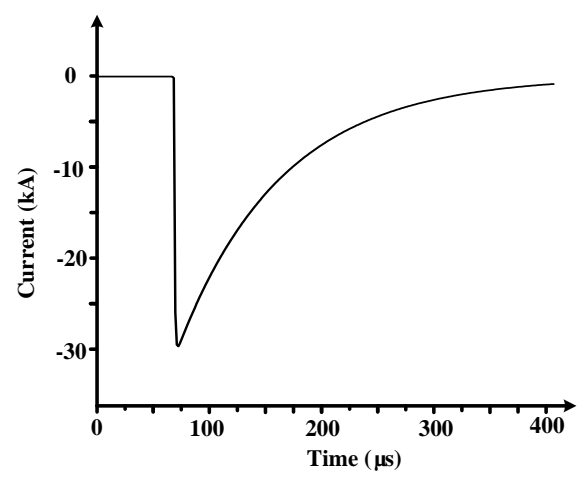

(a) Lightning current

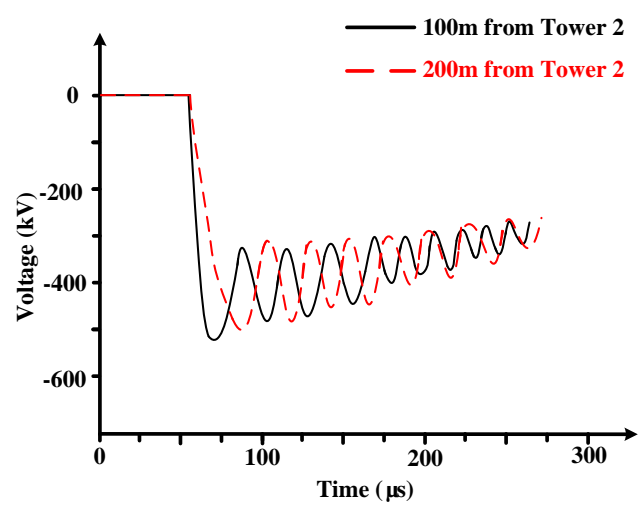

(b) Residual voltage of tower 2 arrester

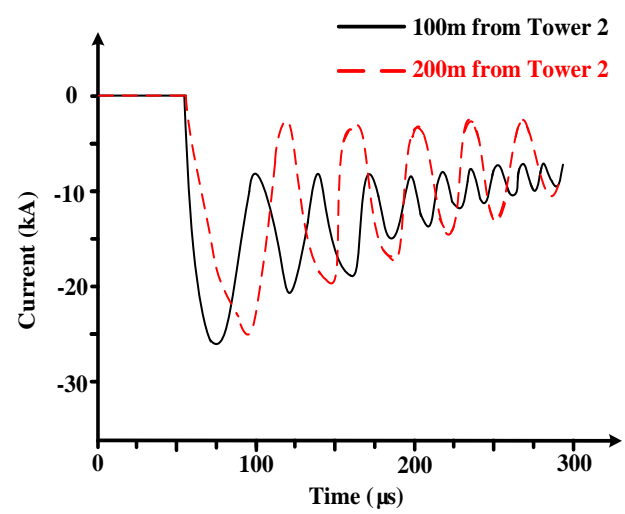

(c) Current flowing through tower 2 arrester Fig. 7. Current waveform of lightning and current 


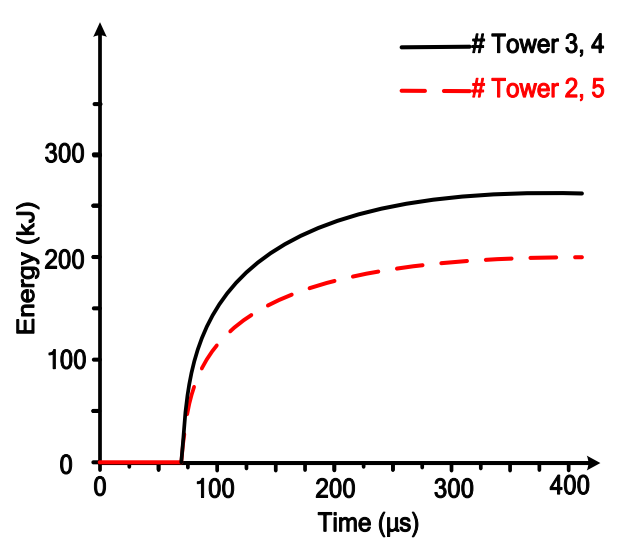

(a) Lightning strike point $200 \mathrm{~m}$ from tower 2

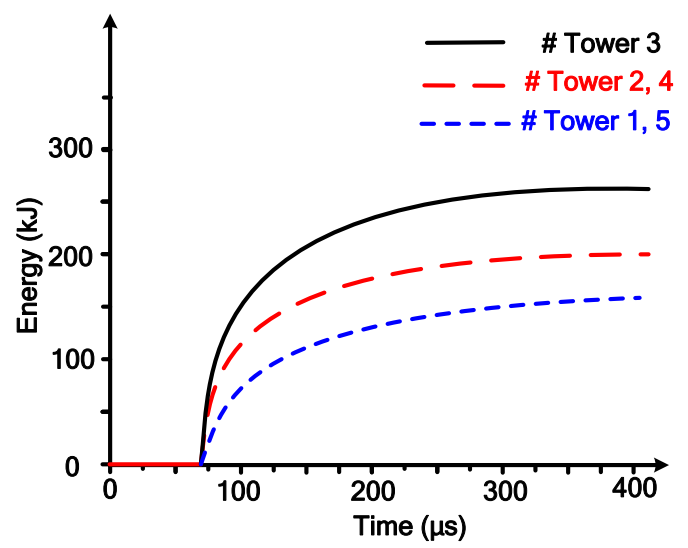

(b) Lightning strike point $100 \mathrm{~m}$ from tower 2

Fig. 8. Energy absorbed by MOA of tower 2

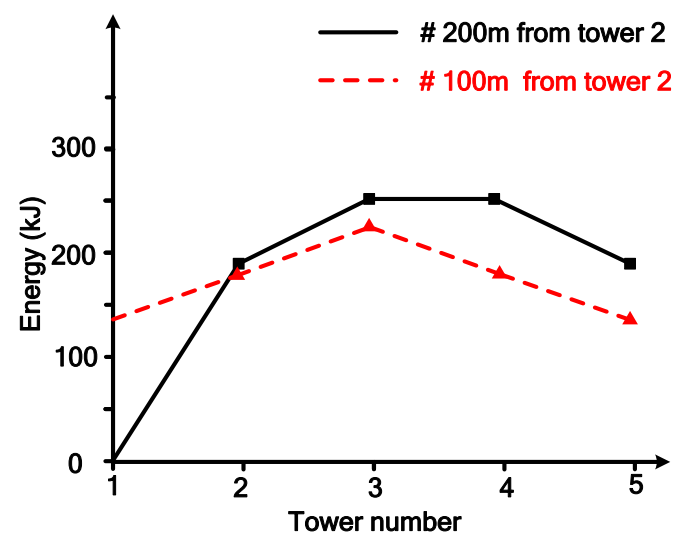

Fig. 9. Influence of strike point on the MOA absorbed energy

Figure 8 shows the energy absorbed by each arrester and Figure 9 shows the influence of strike point on the energy absorbed by nearest MOA. When strike point is $200 \mathrm{~m}$ from tower 2 , the energy absorbed by the arresters are $248 \mathrm{~kJ}$ and $187 \mathrm{~kJ}$. When strike point is $100 \mathrm{~m}$ from tower 2 , the energy absorbed by the arresters are $221 \mathrm{~kJ}$ and $175 \mathrm{~kJ}$ and $140 \mathrm{~kJ}$. It is confirmed that, because of the diversion effect, the lightning current flows through arresters on several adjacent towers, and the striking point can influence the energy absorbed by MOA.

Figure 10 shows the simulated waveforms when a $300 \mathrm{kA}, 2.6 / 50 \mu$ s single pulse lightning current strikes the top of tower 3 . As the tower is connected to the ground by a grounding resistor, most of the lightning current flows into the ground and the transient current flowing to the conductors is $20 \mathrm{kA}$, which will not cause damage to the MOA. As most lightning current is less than $300 \mathrm{kA}$, for transmission lines equipped with arresters, the failure rate of MOA caused by the lightning back flashover is so small that can be neglected.

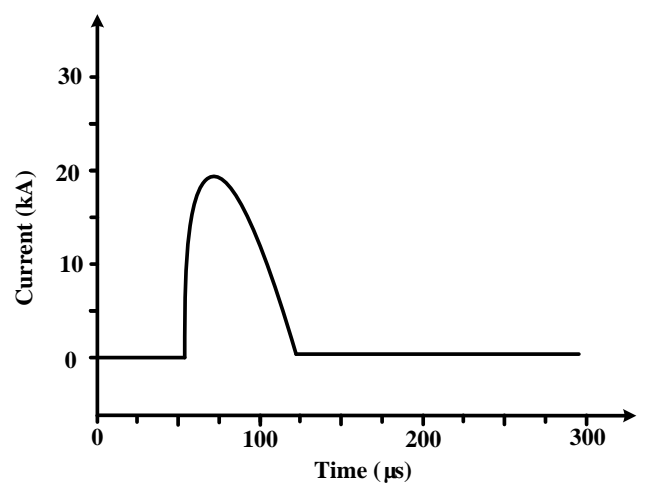

Fig. 10. Influence of strike point on the energy absorbed by MOA

\subsection{Influence of soil resistivity}

In order to represent the multi-stroke process, three continuous impulse currents were used to present lightning flash for simulation. These impulse currents have a waveform of $2.6 / 50 \mu \mathrm{s}$, the time interval between these impulses are $60 \mathrm{~ms}$, and the amplitude of first impulse is $30 \mathrm{kA}$, the second and third impulse is $1 / 4$ of the first one[9]. Assuming that the lightning occurrence point locates at the middle of the span length $(200 \mathrm{~m}$ from tower 2), the variation of MOA absorbed energy with tower grounding resistance is shown in Figure. 11.

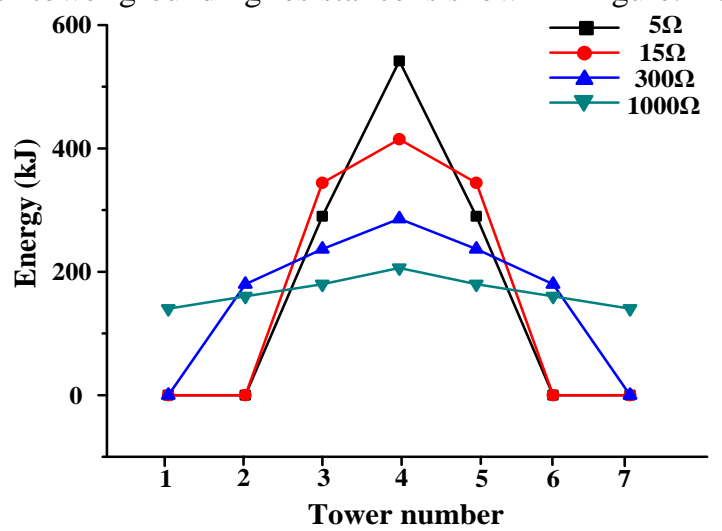

Fig.11. Variation of MOA energy absorption with grounding resistance

As shown in the figure, when the grounding resistance is $5 \Omega$, the max energy absorbed by MOA is $542 \mathrm{~kJ}$. With the increasing of grounding resistance, the diversion effect become more obvious. The lightning current flows through more MOAs into the ground and the max MOA absorbed energy decreases. It can be confirmed that, for unshielded transmission lines equipped with MOAs whole line, failure rate of MOA caused by back flashover can be neglected, the increasing of grounding resistance can alleviate the energy stress of single MOA. Compared with traditional shielded lines, a larger grounding resistance can improve the lightning protection ability of MOA quipped 
unshielded lines, which are more applicable in cold mountainous regions where grounding resistance is hard to be reduced.

\section{Conclusion}

This paper proposes a promising way for lightning and icing protection in high mountainous areas. The simulation model of unshielded transmission line equipped with MOAs was built, the distribution of lightning current flowing through MOAs was obtained, and the variation of MOA absorbed energy with grounding resistance and lightning parameters were analyzed, according to which the following conclusions can be made:

1. When lightning strikes the tower, as the towers are connected to the ground by a grounding resistor, most of the lightning current flows into the ground and the transient current flowing to the conductors are much smaller. The damage rate of MOA caused by back flashover can be neglected.

2. When lightning strikes the conductors, because of the diversion effect, the lightning current flows through several adjacent MOAs to the ground. With the increasing of grounding resistance, the max energy absorbed by single MOA decreases and the lightning current flows through more MOAs. Due to the refraction and reflection effects of lightning current waves, the flash occurrence point influences little on the amplitude of the current flowing through the nearest arrester.
This work is supported by Changsha Science and Technology project in Hunan Province (kq 1804051), and Science and Technology project of State Grid Corporation of China ( 5216A01600W3,5216A01800JG)

\section{References}

1 F. Napolitano, IEEE Trans. Electromagn. Compat., 53, 108, (2011).

2 Y. Zhang, Q. Yang, S. Xie and C. Zhang, IEEE T. Electromagn. C., 43,1, (2019).

3 X. Jiang, S. Fan, Z. Zhang, C. Sun and L. Shu, IEEE T. Dielect. El. In., 25, 919, (2010).

4 S. Visacro, C.R. de Mesquita, R.N. Dias, F.H. Silveira and A. De Conti, IEEE T. Electromagn. C., 54, 1028, (2012).

5 W. Sima, D. Luo, T. Yuan, S. Liu, P. Sun and T. Li, IEEE T. Power Deliver., 33, 2125, (2018).

6 F.H. SilveiraS. Visacro and A. De Conti, IEEE T. Electromagn. C., 55, 1195, (2013).

7 W. Sima, D. Luo, T. Yuan, S. Liu, P. Sun and T. Li, IEEE T. Power Deliver., 33, 2125, (2018).

8 P. N. Mikropoulos and T. E. Tsovilis, IEEE Trans. Dielectr. Electr. Insul., 20, 202, (2013).

9 A. Borghetti, C. A. Nucci, and M. Paolone, IEEE Trans. PowerDeliv., 22, 684, (2007).

10 P. N. Mikropoulos and T. E. Tsovilis, IEEE Trans. Dielectr. Electr. Insul., 20, 202, (2013). 